\title{
Transgenic expression of human gp100 and RANTES at specific time points for suppression of melanoma
}

\author{
K Aravindaram ${ }^{1}, \mathrm{H}-\mathrm{H} \mathrm{Yu}^{1}$, C-W Lan ${ }^{1}, \mathrm{P}-\mathrm{H}$ Wang $^{1}, \mathrm{Y}-\mathrm{H} \mathrm{Chen}^{1}$, H-M Chen ${ }^{1}, \mathrm{H}$ Yagita ${ }^{2}$ and N-S Yang $^{1}$ \\ ${ }^{1}$ Agricultural Biotechnology Research Center, Academia Sinica, Taipei, Taiwan and ${ }^{2}$ Department of Immunology, Juntendo University \\ School of Medicine, Tokyo, Japan
}

The induction of strong cell-mediated immunity against targeted cancer cells is difficult, and often requires specific vaccination schema and the appropriate adjuvants to be effective. The chemokine RANTES has been studied as a vaccine adjuvant in cancer therapy, but specific applications remain to be determined. For gene-based vaccination against B16 melanoma in C57BL/6JNarl mice, initial priming with mouse RANTES cDNA followed $24 \mathrm{~h}$ later by human gp100 DNA vaccination, and later boosting with a viral vector expressing mRANTES and hgp100 strongly suppressed B16/hgp100 primary tumors and lung metastasis. The inclusion of mRANTES in this vaccination regimen gave significantly better suppression of tumor growth, substantially enhanced mouse survival, and led to greater cytotoxic activity of splenocytes against B16/hgp100 cells than vaccination against hgp100 alone. B16/hgp100 melanoma cells were resistant to the ligands TRAIL and FasL in vitro but sensitized to them in vivo owing to the priming effect of cytokines in response to vaccination. Our data demonstrate that co-vaccination with chemokine (mRANTES) and tumorspecific (hgp100) genes in a specific time sequence is more effective at suppressing tumor growth and metastasis than hgp100 alone, and this effect may be mediated by sensitization of tumor cells to death ligands.

Gene Therapy (2009) 16, 1329-1339; doi:10.1038/gt.2009.90; published online 23 July 2009

Keywords: prime-boost; melanoma; chemokine; vaccinia virus; migration; death receptors

\section{Introduction}

A major strategy for cancer vaccines is to raise a cytotoxic immune response, in which host antitumor cytotoxic $\mathrm{T}$ lymphocytes (CTLs) and/or natural killer (NK) cells mediate tumor rejection and/or regression. Processing and presentation of tumor-associated antigens (TAAs) is required for potent priming and activation of antitumor CTLs in the context of appropriate major histocompatibility complex class I molecules by antigen-presenting cells such as dendritic cells (DCs). ${ }^{1}$ Melanoma is one of the few cancers for which multiple TAAs capable of eliciting a specific cellular immune response have been identified, including human gp100 (hgp100), MART-1/ Melan-A, tyrosinase, and tyrosinase-related protein, ${ }^{2-4}$ which are nonmutated self-differentiation antigens associated with melanin synthesis in normal melanocytes. Of these, hgp100 is a promising target antigen. Immunization with hgp100-expressing viral vectors overcame selftolerance to mouse gp100 in C57BL/6 mice because the approach could induce hgp100-specific and murine B16 melanoma-cross-reactive T-cell responses. ${ }^{5-7}$

Furthermore, a number of cytokines (interleukin (IL)$2,-12,-15,-18,-21$, and -24 ) have been tested as adjuvants in combination with DNA vaccines, with varying degrees of enhanced antitumor immunity. ${ }^{8,9}$ We earlier reported

Correspondence: Dr N-S Yang, Agricultural Biotechnology Research Center, Academia Sinica, No. 128, Section 2, Academia Road, Nangang, Taipei 115, Taiwan.

E-mail: nsyang@gate.sinica.edu.tw

Received 20 November 2008; revised 1 March 2009; accepted 2 March 2009; published online 23 July 2009 that granulocyte macrophage colony-stimulating factor (GM-CSF) DNA enhanced antitumor immunity induced by hgp100 DNA vaccination in a mouse melanoma model. ${ }^{10}$ However, in general, such adjuvant cytokines have not been shown to confer significant and consistent enhancement of antigen-specific cell-mediated immunity with DNA vaccine approaches, and the ability of tumors to escape the immune system has been a major obstacle to the development of effective tumor immunotherapy.

Chemokines are chemo-attractant cytokines that regulate the trafficking and activation of leukocytes, especially DCs and B and T cells, thereby promoting effective innate and adaptive immune responses. ${ }^{11-13}$ One of the most studied is RANTES (CCL5), a member of the CC family, which induces leukocyte migration by binding to specific receptors CCR1, CCR3, CCR4, and CCR5. It acts on a range of cell types, including basophils, eosinophils, T cells, NK cells, DCs, and mast cells. ${ }^{14}$ RANTES also has a key function in antitumor ${ }^{15,16}$ and antiviral ${ }^{17}$ immune responses, along with perforin and granzyme A. ${ }^{17,18}$ Even though many researchers have reported the potential of RANTES as a vaccine adjuvant, an optimized and clinically relevant protocol remains to be determined.

Considering the above concerns, we consider that the sequence of vaccination is critically important to induce strong and long-lasting cell-mediated immunity. DNA vaccines have been shown to prime efficiently but often cannot boost a very strong $\mathrm{CD}^{+}$response in addition to the $\mathrm{CD}^{+}$T-cell response. Heterologous prime-boost immunization strategies such as modified vaccinia virus ankara (MVA) boosting induce higher levels of effector 
T-cell responses in vaccinated animals and humans than homologous boosting with the same vaccine. ${ }^{19,20}$

With regard to the molecular mechanisms of the CTL function, death-receptor ligands such as tumor-necrosis factor- $\alpha$ (TNF- $\alpha)$, Fas ligand (FasL), and TNF-related apoptosis inducing ligand (TRAIL) may be mediators of cytotoxic activity. ${ }^{21}$ We earlier reported that TRAIL acts as a tumor suppressor molecule in vivo by inducing apoptotic death of tumor cells. ${ }^{22,23}$ We also showed that inactivation and neutralization of perforin, FasL, and TRAIL completely inhibited NK cell cytotoxicity against mouse fibrosarcoma L929 target cells. ${ }^{24}$

In this study, we tested whether the delivery of RANTES as an adjuvant before hgp100 antigen vaccination could attract immune cells to the skin vaccination site to greatly enhance the effect of hgp100 vaccination against melanoma. To further augment the antitumor immune responses, we also adopted a heterologous prime-boost regimen (that is MVA boost). We also show that this combinational therapy approach can enhance the antitumor cytolytic activity of the vaccine-induced effector $\mathrm{T}$ cells and that this signaling is mediated by TRAIL and FasL.

\section{Results}

Human gp100 transgene expression in vitro and in vivo To study the effect of a hgp100 gene-based vaccine in mice, we cloned the hgp100 cDNA into a mammalian expression vector and analyzed its transgenic expression in B16/hgp100 melanocytic tumor cells (in vitro) and mouse skin (in vivo) at 24 and $48 \mathrm{~h}$ by RT-PCR to confirm the transcriptional expression of hgp100 (Figure 1a). Expressed hgp100 mRNA was found in stably transfected B16/hgp100 tumor cells and transfected mouse skin 24 and $48 \mathrm{~h}$ after gene gun bombardment, and no hgp100 mRNA was found in empty vector-transfected skin tissue.

\section{Transgenic mRANTES facilitates the migration of immune cell subsets in vitro}

Functional expression of mRANTES transgene after transfection of HEK 293 cells with mRANTES cDNA expression plasmid was determined by ELISA for mRANTES protein in the culture supernatant $48 \mathrm{~h}$ after transfection (95\% CI $=131.4-143.9 \mathrm{ng} \mathrm{ml}^{-1} ; \quad P<0.0001$; Figure 1b). Immature but not mature DCs showed significant migration activity (95\% CI=93.14-113.3; $P<0.0001$; Figure 1c). CD4 ${ }^{+}$T cells, and to a lesser extent $\mathrm{CD}^{+} \mathrm{T}$ cells, also exhibited significant migration $(95 \%$ $\mathrm{CI}=2$ 29.35-48.25; $P<0.0001)$.

\section{Effect of mRANTES and hgp100 vaccination on tumor growth and survival in mice}

In the subcutaneous tumor model, B16/hgp100 tumors grew significantly more slowly in mRANTES- and hgp100-immunized mice than in empty vector-treated mice (Figure 2a). Tumors in the mRANTES $(0 \mathrm{~h})+$
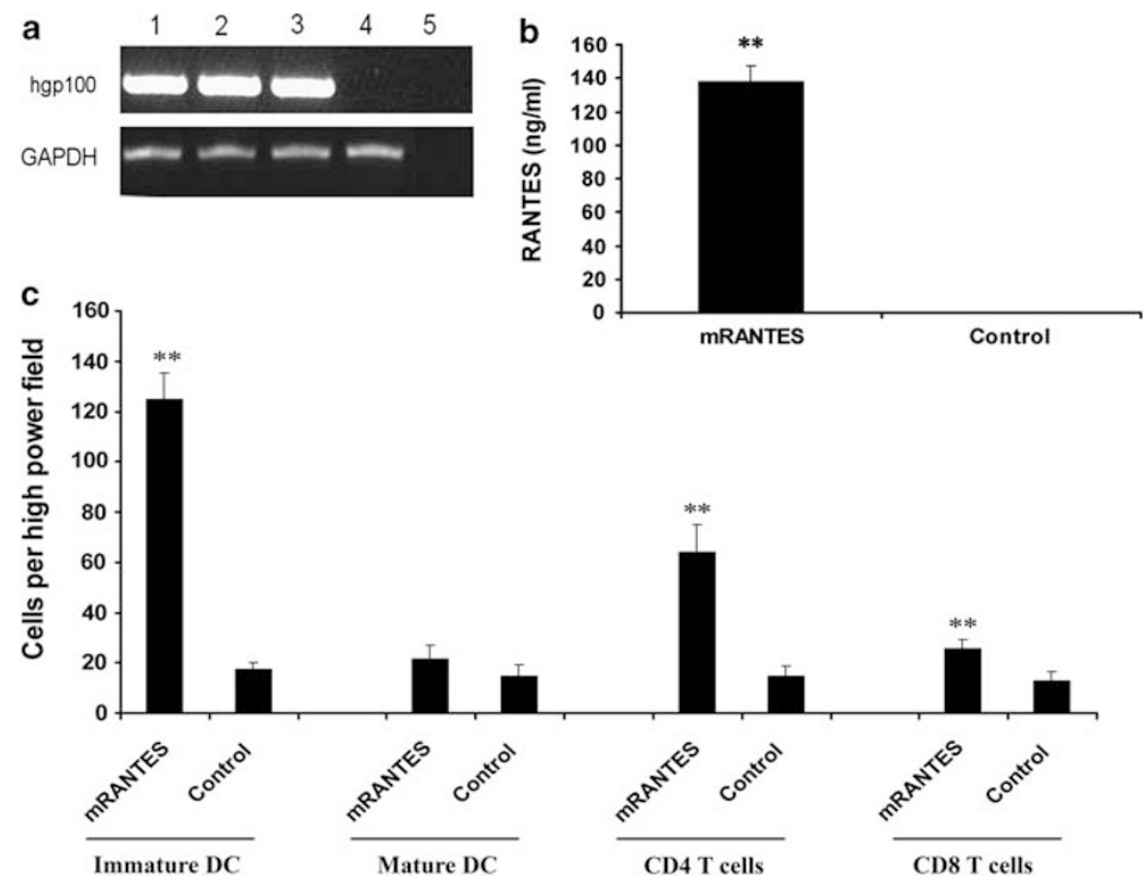

Figure 1 Transgene expression of hgp100 and mRANTES cDNA vectors in vitro and in vivo. (a) The abdominal skin tissue of C57BL/6 mice was bombarded with $3 \mu \mathrm{g}$ of hgp100 plasmid DNA; skin samples were removed at specific time intervals, and total RNA was extracted for RT-PCR. Lane 1, RNA from B16/hgp100 cells stably transfected with hgp100; lanes 2 and 3, RNA from skin transfected with hgp100 cDNA at 24 and $48 \mathrm{~h}$ post bombardment, respectively; lane 4, RNA from skin transfected with empty vector; lane 5, negative control sample (without RNA). The housekeeping gene GAPDH was used as an internal control. (b) HEK293 cells were transfected with mRANTES cDNA expression plasmid. Functional expression of mRANTES was determined by ELISA. Experiments were performed three times in triplicate. Data are means with upper $95 \%$ confidence intervals. ${ }^{* *} P<0.0001$. (c) Migration of subsets of mouse DCs and T cells in response to mRANTES culture supernatant of mRANTES- or mock-transfected HEK293 cells was assessed by chemotaxis assay. Three independent experiments were performed, and at least five microscopic fields per experiment were examined. Data are means with upper $95 \%$ confidence intervals. ${ }^{* *} P<0.0001$. 

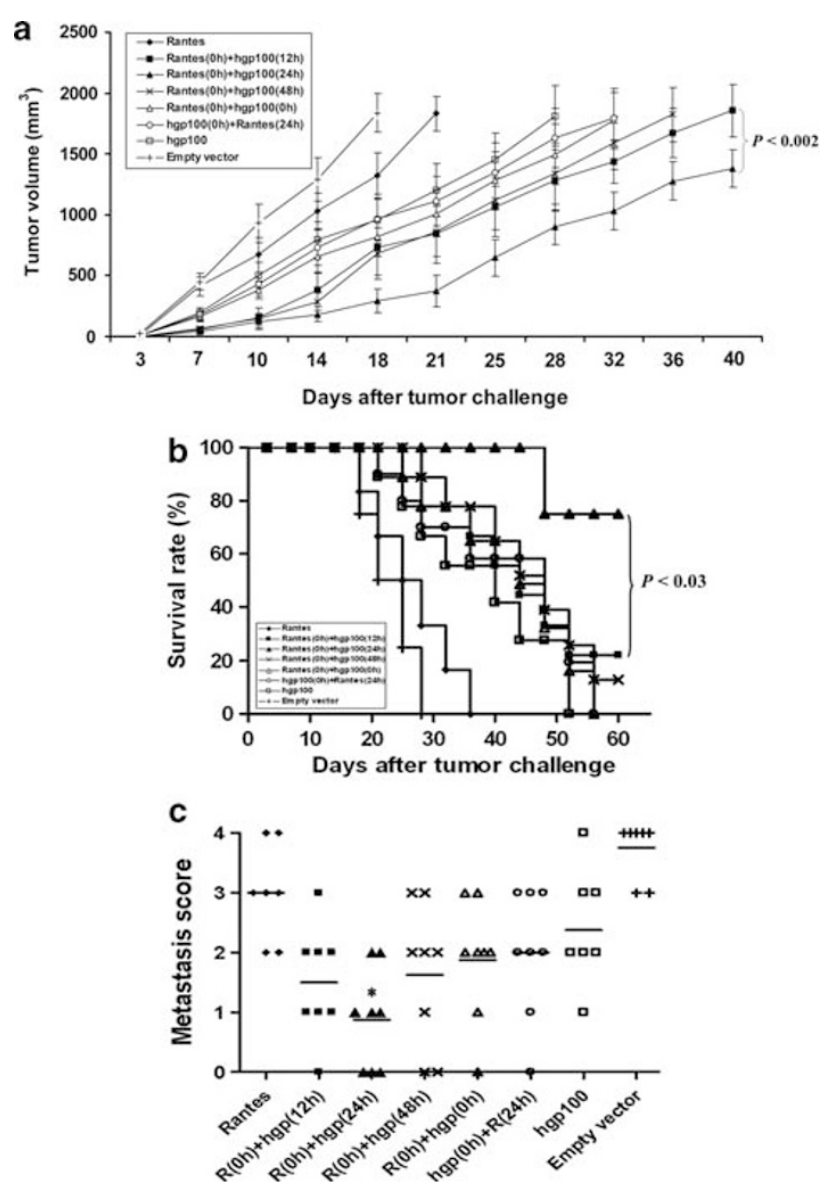

Figure 2 Protective immunity induced by vaccination with mRANTES and hgp100 cDNA vectors at specific times in primary tumor and metastasis models. (a) Primary tumor model. Vaccination protocols are described in 'Materials and methods'. Volumes of B16/hgp100 tumors derived from mice vaccinated with mRANTES and hgp100 vector and control mice were measured at the indicated times in a blinded manner. Data are means with upper 95\% confidence intervals ( $n=8$ mice per group). $P=0.002$, mRANTES $(0 \mathrm{~h})+\mathrm{hgp} 100(24 \mathrm{~h})$ group compared with mRANTES $(0 \mathrm{~h})+\mathrm{hgp} 100(12 \mathrm{~h})$ group at 40 days after tumor challenge. (b) Survival was observed after challenge with B16/hgp100 tumor cells (i.e. day 0 on graph). $P<0.03$, log-rank test of Kaplan-Meier curves, mRANTES $(0 \mathrm{~h})+\mathrm{hgp} 100(24 \mathrm{~h})$ group compared with mRANTES $(0 \mathrm{~h})+\mathrm{hgp} 100(12 \mathrm{~h})$ group at 60 days after tumor challenge. (c) Metastasis model. C57BL/6 mice were divided into eight experimental groups ( $n=8$ each), injected intravenously with B16/ hgp100 cells $\left(10^{5}\right.$ cells $/ 100 \mu \mathrm{l} /$ mouse $)$ on day 0 and with test vaccine/adjuvant sets as described in 'Materials and methods'. The experiment was terminated on day 21 , and tumor metastasis into the lung was scored by estimating the percentage surface area covered by metastasis as follows: 0 , no metastases and $1,<25 \%$; 2 , 25-50\%; 3, 50-75\%; and $4>75 \%$ metastasis, represented by individual symbols for each treatment group. Bars = mean metastasis scores for each group. ${ }^{*} P=0.0041$, mRANTES $(0 \mathrm{~h})+\mathrm{hgp} 100$ $(24 \mathrm{~h})$ compared with hgp100 alone treatment. All experiments repeated at least twice.

hgp100(24 h) treatment group grew to approximately $290 \mathrm{~mm}^{3}\left(95 \% \mathrm{CI}=192-387 \mathrm{~mm}^{3}\right)$ at 18 days after inoculation, whereas tumors with empty vector (control) treatment grew to approximately $1837 \mathrm{~mm}^{3} \quad(95 \%$ $\left.\mathrm{CI}=1683-1993 \mathrm{~mm}^{3} ; P<0.0001\right)$. At 40 days after tumor inoculation, tumors in the mRANTES(0 h)+hgp100(24 h) group grew to $1380 \mathrm{~mm}^{3}\left(95 \% \mathrm{CI}=1225-1535 \mathrm{~mm}^{3}\right)$, whereas those with mRANTES(0 h)+hgp100(12 h) treatment grew to $1855 \mathrm{~mm}^{3}\left(95 \% \mathrm{CI}=1641-2069 \mathrm{~mm}^{3}\right.$; $P=0.002$ ).

Survival time of the vaccinated mice was significantly longer than control, especially with mRAN$\operatorname{TES}(0 \mathrm{~h})+\mathrm{hgp} 100(24 \mathrm{~h})$ treatment, which showed $75 \%$ survival 60 days after tumor challenge, whereas mice treated with empty vector died within 28 days after tumor challenge. Mice with the highest survival rate, with mRANTES $(0 \mathrm{~h})+\mathrm{hgp} 100(24 \mathrm{~h})$ treatment, showed regression of tumor (hazard ratio $(\mathrm{HR})=7.0$, 95\% CI $=1.155-19.43 ; P=0.03)$ than with mRANTES $(0 \mathrm{~h})+$ hgp100(12 h) treatment, as shown by KaplanMeier survival analyses and log-rank tests (Figure $2 \mathrm{~b}$ ).

Lung metastasis of B16/hgp100 melanoma cells was significantly reduced by this heterologous primeboost strategy (Figure 2c). Treatment with mRANTES $(0 \mathrm{~h})+$ hgp100(24 h) produced a significantly lower number of tumor metastases $(P=0.004)$ than with hgp100 alone.

\section{Involvement of specific immune cell subsets in vaccine efficiency}

During immunization and tumor challenge, mice were injected intraperitoneally with either anti-CD4, -CD8, or -NK1.1 mAb to deplete the respective cell class. NK cells and $\mathrm{CD}^{+} \mathrm{T}$ cells are apparently required for the observed protective activity (Figure 3). On the other hand, the survival rate was 10 days higher in $\mathrm{CD}^{+}{ }^{+}$ depleted mice compared with both the $\mathrm{CD}^{+} \mathrm{T}$ cell and $\mathrm{NK}$ cell-depleted mice. Depletion of $\mathrm{CD}^{+}$and $\mathrm{NK}$ cells from tumor bearing mice completely blocked the protective effect of mRANTES $(0 \mathrm{~h})+\mathrm{hgp} 100(24 \mathrm{~h})$ genebased vaccination. These results indicate that hgp100specific $\mathrm{CD}^{+}$CTLs and NK cells are critical for inhibition of tumor growth, and that $\mathrm{CD}^{+} \mathrm{T}$ cells can contribute to priming and activation of antitumor immunity.

\section{Immune responses induced by mRANTES+hgp100 gene vaccination}

To characterize the immune response induced by mRANTES+hgp100 gene vaccination, we isolated splenocytes from immunized mice after the second boosting and examined production of cytokines and CTL activity in response to B16/hgp100 melanoma cells. Enzymelinked immunospot (ELISPOT) assay showed much higher numbers of IFN- $\gamma$-secreting cells with mRANTES $(0 \mathrm{~h})+\operatorname{hgp} 100(24 \mathrm{~h})$ treatment $(95 \% \quad \mathrm{CI}=107-170$; $P=0.0003)$ than with hgp100 cDNA alone on stimulation with mitomycin C (MMC)-inactivated B16/hgp100 cells in vitro (Figure $4 \mathrm{a}$ ). There was no significant difference in the secretion of IFN- $\gamma$ from nonstimulated splenocytes between vaccinated and nonvaccinated groups (data not shown).

We next tested the cytolytic activity of splenocytes toward B16/hgp100 melanoma cells. Splenocytes from mice treated with the mRANTES transgene delivered before hgp100 cDNA transfection had significantly greater capacity to kill B16/hgp100 cells (\% lysis) than those from mice treated with hgp100 alone at a 100:1 ratio of effector:target cells $(95 \% \quad \mathrm{CI}=23.8-32 \%$; $P<0.0001$ for mRANTES(0 h)+hgp100(24 h); Figure 4b). As well, mRANTES(0 h)+hgp100(24h) and mRANTES(0 h)+ hgp100(12 h) treatment resulted in a higher splenocyte 


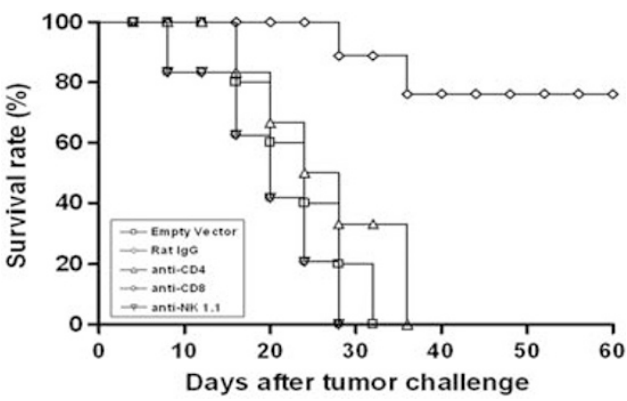

Figure 3 Determination of immune cell subsets responsible for the protective immunity induced by DNA vaccination with mRANTEShgp100 vectors. C57BL/ 6 mice $(n=7)$ were immunized as described in 'Materials and methods' and inoculated with B16/hgp100 cells $\left(10^{5} /\right.$ mice) 1 week after immunization. Anti-CD4 (GK1.5), -CD8 (53-6.7), and -NK1.1 (PK136) antibodies were intraperitoneally injected as described in 'Materials and methods'. Specific depletion of CD4 or CD8 T-cell subset and NK cells was monitored by flow cytometry, which showed $>90 \%$ depletion of splenocytes at the time of immunization or tumor challenge. $P=0.002$ for rat IgG compared with anti-CD4; $P<0.0001$ for rat IgG compared with control, anti-CD8, and anti-NK1.1. Experiments repeated at least twice.
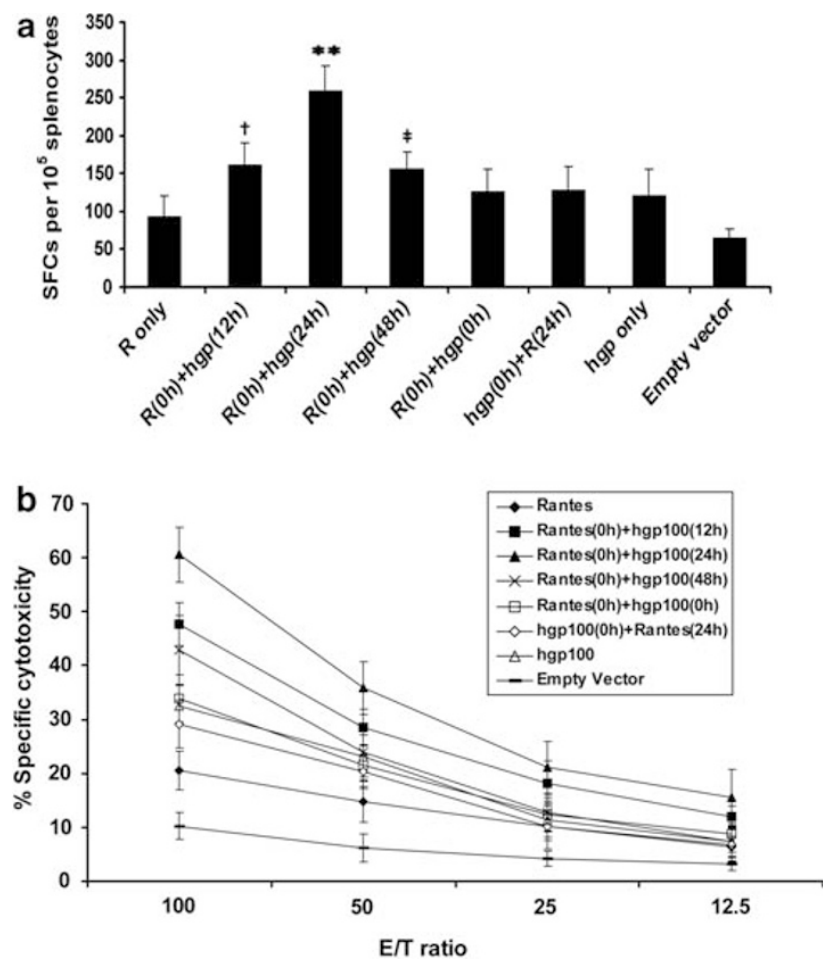

Figure 4 mRANTES+hgp100 gene-based vaccination therapy induces hgp100-specific T-cell responses. (a) IFN- $\gamma$-secreting T cells were quantified ex vivo by ELISPOT assay with fresh splenocytes collected 2 weeks after the second boosting from vaccinated or control mice. Results are expressed as IFN- $\gamma$-positive spot-forming cells (SFCs) $/ 10^{5}$ spleen cells. Data are means with upper $95 \%$ confidence intervals of three independent experiments with triplicate wells for each treatment. ${ }^{\dagger} P=0.01 ;{ }^{* *} P=0.0003$; ${ }^{\ddagger} P=0.02$, as compared with hgp100 alone. (R, RANTES; hgp, hgp100). (b) Generation of tumor-specific cytotoxic $\mathrm{T}$ lymphocytes against B16/hgp100 (target) cells. Fresh splenocytes obtained from mice vaccinated with mRANTES+hgp100 or control mice 2 weeks after the last immunization were used as effector cells in a nonradioactive DELFIA EuTDA cytotoxicity assay. Splenocytes were tested against target cells at the indicated effector:target ratios, and results are expressed as percent cytotoxicity. Data are means with upper $95 \%$ confidence intervals of three independent experiments for each treatment. killing activity than hgp100-alone treatment at 50:1, 25:1, and 12.5:1 cell ratios, but this finding was not observed for mRANTES $(0 \mathrm{~h})+\mathrm{hgp} 100(48 \mathrm{~h})$ treatment. We believe that this killing activity may result not only from both $\mathrm{CD}^{+} \mathrm{T}$ cells and NK cells but also from $\mathrm{CD}^{+} \mathrm{T}$ cells because the protective effect of $\operatorname{mRANTES}(0 \mathrm{~h})+$ hgp100(24 h) vaccination was completely blocked by the depletion of $\mathrm{CD}^{+} \mathrm{T}$ cells and NK cells and also slightly by $\mathrm{CD}^{+} \mathrm{T}$-cell depletion (Figure 3 ).

To further characterize the immune responses, we used ELISA to determine the release of cytokines IFN- $\gamma$, IL-10, TNF- $\alpha$, and GM-CSF at $48 \mathrm{~h}$ after stimulation of splenocytes with MMC-inactivated B16/hgp100 cells. IFN- $\gamma$ secretion with mRANTES(0 h)+hgp100(12 h) (95\% CI $\left.=115.1-241.6 \mathrm{pg} \mathrm{ml}^{-1} ; P=0.001\right), \operatorname{mRANTES}(0 \mathrm{~h})$ +hgp100(24 h) (95\% CI $\left.=232.6-344 \mathrm{pg} \mathrm{ml}^{-1} ; P=0.0001\right)$, and mRANTES(0 h)+hgp100(48 h) (95\% CI =73.52$\left.209.1 \mathrm{pg} \mathrm{ml}^{-1} ; \quad P=0.004\right)$ was significantly higher than with hgp100 alone (Figure 5a). In contrast, IL-10 secretion was lower with mRANTES(0 h)+hgp100(12 h) (95\% $\mathrm{CI}=-17.2$ to $-6.7 \mathrm{pg} \mathrm{ml}^{-1} ; P=0.003$ ), mRANTES $(0 \mathrm{~h})+\mathrm{hgp} 100(24 \mathrm{~h}) \quad\left(95 \% \mathrm{CI}=-10.0\right.$ to $-0.21 \mathrm{pg} \mathrm{ml}^{-1}$; $P=0.04)$, and mRANTES( $0 \mathrm{~h})+\mathrm{hgp} 100(48 \mathrm{~h})(\mathrm{CI}=-8.8$ to $-0.52 \mathrm{pg} \mathrm{ml}^{-1} ; P=0.03$ ) than with hgp100 alone (Figure $5 b)$. Two other important cytokines, TNF- $\alpha$ and GM-SCF, were also secreted in lager amounts with combinational treatment than with hgp100 alone. Secretion of the pro-inflammatory cytokine TNF- $\alpha$ was significantly higher with mRANTES(0 h)+hgp100(24 h) treatment (95\% CI $\left.=75.4-124.2 \mathrm{pg} \mathrm{ml}^{-1} ; P=0.0003\right)$ but not with mRANTES $(0 \mathrm{~h})+$ hgp100(48 h) treatment than with hgp100 alone (Figure 5c). Treatment with mRANTES $(0 \mathrm{~h})+$ hgp100(24 h) (95\% CI $\left.=190.1-239.1 \mathrm{pg} \mathrm{ml}^{-1} ; \quad P<0.0001\right)$ produced higher GM-CSF secretion than with hgp100 alone (Figure 5d). Thus, the times of application of hgp100 after mRANTES gene transfection were critically important for the enhanced hgp100-specific cell-mediated immunity.

\section{Immunohistochemical analysis of immune cell migration in mouse skin}

We examined the migration of $\mathrm{CD}^{+}, \mathrm{CD}^{+}, \mathrm{NK}-1.1$, and CD11c-expressing immune cells to the vaccination site $24 \mathrm{~h}$ after vaccination with RANTES or empty vector transgenes. Immunohistochemical analysis of mouse skin showed that RANTES treatment recruited significant numbers of various immune cells compared with empty vector-treated or normal mice (Figure 6). Migration of immune cells was also observed at 12 and $48 \mathrm{~h}$ post treatment with RANTES, but less than at $24 \mathrm{~h}$ (data not shown).

Involvement of TRAIL and FasL in the antitumor effect Tumor cells were incubated with an mTRAIL genetransfected cell line (mTRAIL-2PK3) and an mFasL genetransfected cell line (mFasL-L5178Y) in a DELFIA EuTDA cytotoxicity assay. B16/hgp100 cells were quite resistant, but fibrosarcoma L929 cells were highly sensitive to mTRAIL and mFasL in vitro (Figure $7 \mathrm{a}$ ). However, CTL activity of the immune splenocytes was substantially reduced when neutralizing anti-mTRAIL and anti-mFasL mAbs were added to the cytotoxicity assay. All effector cells from both vaccinated and empty vector-treated mice showed decreased CTL activity in 

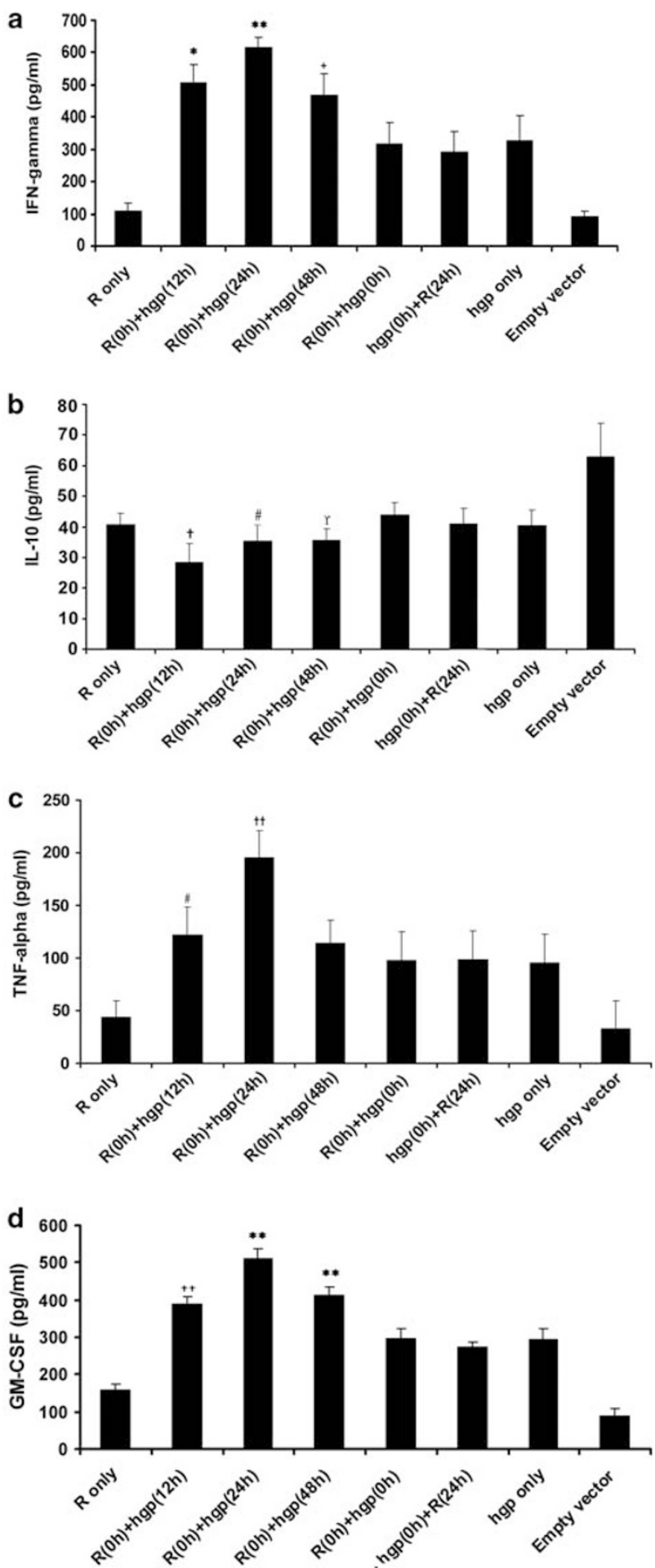

Figure 5 Effect of mRANTES+hgp100 gene-based vaccination on cytokine secretion in B16/hgp100 melanoma cells. Mice were immunized with mRANTES and hgp100 vectors at different times, and boosted twice with MVA-mRANTES and MVA-hgp100 at 2-week intervals. Two weeks after the last immunization, splenocytes were collected from immunized or control mice and co-cultured with mitomycin C (MMC)-treated B16/hgp100 tumor cells. Supernatants were collected for measurement of (a) IFN- $\gamma$, (b) IL-10, (c) TNF- $\alpha$, and (d) GM-CSF at $48 \mathrm{~h}$ after co-culturing. Data are means with upper $95 \%$ confidence intervals for three mice for each treatment group of triplicate samples. ${ }^{*} P=0.001 ; \quad{ }^{*} P=0.0001 ; \quad{ }^{*} P=0.004 ; \quad{ }^{\dagger} P=0.003 ; \quad{ }^{\Upsilon} P=0.03$; ${ }^{\sharp} P=0.04 ;{ }^{*} P=0.0003$ compared with hgp100 alone. Data are means with upper 95\% confidence intervals (R, mRANTES; hgp, hgp100).
B16/hgp100 cells, which indicates that mTRAIL and mFasL are important in CTL activity in B16/hgp100 tumor cells (Figure $7 \mathrm{~b}$ ). To determine the role of mTRAIL and mFasL in vivo, we administered neutralizing anti-mTRAIL and anti-mFasL mAbs to mRANTES $(0 \mathrm{~h})+\mathrm{hgp} 100(24 \mathrm{~h})$ vaccinated mice. As expected, the mAb-treated group survived for a long time, but the protective effect of the mRANTES $(0 \mathrm{~h})+\mathrm{hgp} 100(24 \mathrm{~h})$ vaccination was abolished by anti-mTRAIL or antimFasL mAb (Figure 7c). Interestingly, B16/hgp100 cells pretreated with GM-CSF and TNF- $\alpha$ were highly susceptible to mTRAIL and mFasL (Figure 7d). In addition to their combination, individual pre-treatment with GM-CSF or TNF- $\alpha$ in B16/hgp100 cells also produced susceptibility to mTRAIL and mFasL (data not shown). mFasL/L5178Y had a higher cytotoxic effect (95\% CI $=-25.8$ to $-16.8 \% ; P=0.0002)$ than mTRAIL/ 2PK-3, whereas the combination of mTRAIL and mFasL transfectants gave a significantly higher cytotoxic effect (95\% CI $=-20.4 \%$ to $-10.8 \% ; P=0.0008)$ than $\mathrm{mFasL} /$ L5178Y. The addition of anti-mTRAIL and anti-mFasL mAbs completely abolished the cytotoxicity. These results suggest that the B16/hgp100 melanoma cells were sensitized to mFasL- and mTRAIL-mediated cytotoxicity by effector T-cell-derived cytokines such as TNF- $\alpha$ and GM-CSF.

\section{Discussion}

Currently, a key experimental cancer therapy approach is to stimulate tumor-specific immunity by means of the potent antigen-presenting capacity of DCs to $\mathrm{T}$ cells, which results in very strong cytotoxicity against tumor cells. In this study, we investigated the effect of different time periods of application of the adjuvant mRANTES in gene-based cancer vaccination with hgp100, to enhance tumor-specific immunity by prime-boost vaccinations with an MVA vector system. Various studies have shown that the RANTES chemokine recruits $\mathrm{Th}_{1}$-type $\mathrm{T}$ cells, and has a major function in the attraction of immature DCs and NK cells in vitro and in vivo. ${ }^{16,25,26}$ In this study, we observed the migration of immature DCs and both $\mathrm{CD}^{+}$and $\mathrm{CD}^{+} \mathrm{T}$ cells stimulated by mRANTES in vitro (Figure 1c), which suggested that application of mRANTES gene before hgp100 vaccination at the same site might facilitate the induction of hgp100-specific immune response by migration of both DCs as antigen-presenting cells and $\mathrm{T}$ cells as responder cells.

In our subcutaneous tumor model, we found a significant reduction in tumor growth with mRANTES priming, which varied depending on whether it was applied before or after the hgp100 cDNA vaccine. Compared with the other treatments tested, mRANTES $(0 \mathrm{~h})+$ hgp100(24 h) gave the best tumor suppression and prolonged survival in test mice, whereas mRANTES applied $12 \mathrm{~h}$ or $48 \mathrm{~h}$ before hgp100 vaccination showed less but still significant tumor suppression than mRANTES applied at the same time or after hgp100 cDNA vaccination. The possibilities that DCs, T cells, and NK cells may be recruited to the vaccination site to participate in antitumor immunities may warrant future investigations. Several studies have earlier shown that introduction of a single chemokine, such as CCL1, CCL2 
(monocyte chemoattractant protein-1 (MCP-1)), CCL3 (macrophage inflammatory protein-1 $\alpha$ (MIP-1 $\alpha)$ ), RANTES, CCL16 (human $\beta$ CC chemokine 4 (HCC-4)), CCL19 (MIP-3 $\beta$ ), CCL20 (MIP-3 $\alpha$ ), CCL21 (6Ckine), or a combination thereof, can effectively induce tumor regression and immunity to subsequent tumor challenge. ${ }^{27-31}$ As well, other reports have shown a combination of chemokine(s) with cytokine(s) or TAA to be effective in tumor regression. ${ }^{13,28,30,32}$ In our current metastasis model, the application of mRANTES( $0 \mathrm{~h})+\mathrm{hgp} 100(24 \mathrm{~h})$ was the most effective in reducing lung metastasis.

The antitumor effect was highly dependent on $\mathrm{CD}^{+} \mathrm{T}$ cells and NK cells but also required the participation of $\mathrm{CD}^{+} \mathrm{T}$ cells. Earlier studies have shown that different chemokines may act on different immune cell subsets; for example, CCL21 acts on CD4 ${ }^{+}$and $\mathrm{CD}^{+} \mathrm{T}^{+}$cells ${ }^{30}$ or $\mathrm{NK}$ cells, ${ }^{31}$ and CCL19 mediates its effect through CD4 ${ }^{+}$T cells and NK cells. ${ }^{29}$ Recent studies have shown that $\mathrm{CD}^{+}$and $\mathrm{CD}^{+} \mathrm{T}$ cells are essential for induction of tumor-specific immunity in cancer vaccine approaches. ${ }^{33,34}$ In our present vaccine strategy, we showed high CTL activity against B16/ hgp100 melanoma, results that are consistent with those of other immunotherapeutic studies testing CCL21 in lung cancer $^{33}$ or MIP-1 $\alpha$ in B16 melanoma. ${ }^{35}$ On in vitro stimulation of splenocytes with MMC-inactivated B16/ hgp100 melanoma cells, vaccinated groups showed higher levels of IFN- $\gamma$, TNF- $\alpha$, and GM-CSF and lower levels of IL10 than the empty vector group. These results suggest that the immune response driven by the mRANTES+hgp100 gene vaccination may be mediated by $\mathrm{Th}_{1}$ cells producing IFN- $\gamma$, TNF- $\alpha$, and GM-CSF and a concomitant decrease in IL-10 levels $\left(\mathrm{Th}_{2}\right)$. Earlier studies have shown that produc-

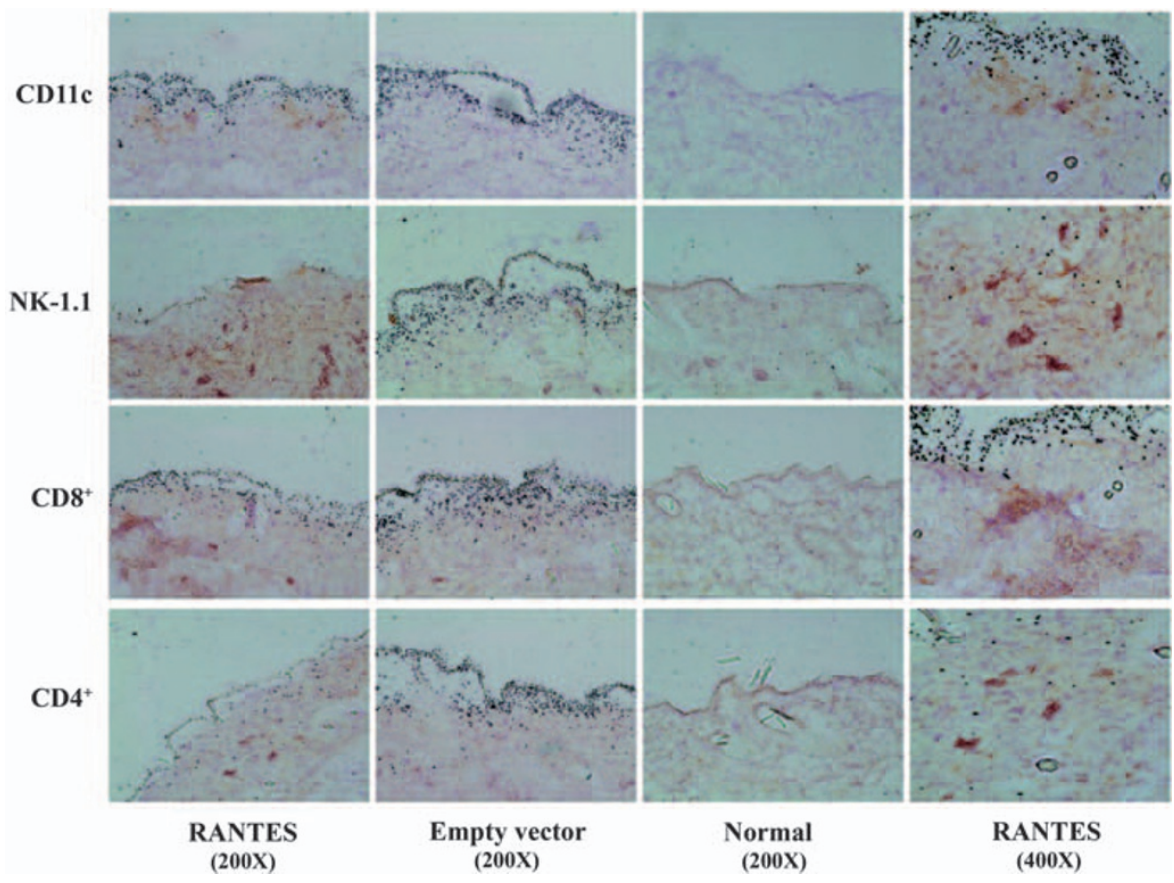

Figure 6 Immunohistochemical staining analysis of immune cell types present at the vaccination site of mouse skin tissue, tested at $24 \mathrm{~h}$ after transfection with transgene RANTES, the empty vector, or untreated as in normal mice. Immunostaining of mouse skin at the cellular level shows dark brown color-stained (CD4 ${ }^{+}, \mathrm{CD}^{+}, \mathrm{NK}-1.1$, and CD11c) cells were induced or increased in RANTES gene-treated vaccination site, compared with the empty vector-treated or untreated (normal) mouse skin tissue. Black spots represent the gold particles delivered after gene-gun bombardment.

Figure 7 Contribution of death-receptor ligands to cytotoxic T-lymphocyte activity in B16/hgp100 melanoma cells. (a) Cytotoxic activity of mTRAIL/2PK-3, mFasL/L5178Y, or both were tested in B16/hgp100 and L929 target cells at an effector:target ratio of 20. Data are means with upper $95 \%$ confidence intervals. Similar results were obtained from three independent experiments. (b) Involvement of mTRAIL and mFasL in CTL activity in B16/hgp100 melanoma cells. Two weeks after immunization, splenocytes collected from vaccinated (mRANTES $(0 \mathrm{~h})+$ hgp100(24 h)) or control mice were blocked with anti-mTRAIL and/or anti-mFasL at $10 \mu \mathrm{g} \mathrm{ml}^{-1}$ and underwent nonradioactive DELFIA EuTDA cytotoxicity assay against B16/hgp100 target cells at an effector:target ratio of $50 .{ }^{\dagger} P=0.003 ;{ }^{*} P=0.001 ;{ }^{\sharp} P=0.0004$; ${ }^{+} P=0.004 ;{ }^{++} P=0.0005 ;{ }^{* *} P<0.0001 ;{ }^{\# \# P=0.0002 ;}{ }^{\ddagger \ddagger} P=0.0007 ;{ }^{\ddagger} P=0.002 ;{ }^{\dagger} P=0.0003 ;{ }^{\Upsilon} P=0.008$ compared with data for rat IgG (control). Data are means with upper $95 \%$ confidence intervals. Similar results were obtained from two independent experiments. (c) Importance of mTRAIL and mFasL in the anti-tumor effect elicited by the mRANTES-hgp100 combinational vaccination (mRANTES $(0 \mathrm{~h})+\mathrm{hgp} 100(24 \mathrm{~h}))$ therapy in B16/hgp100 melanoma cells. C57BL/6 mice with a B16/hgp100 tumor were vaccinated, and also received anti-mTRAIL or anti$\mathrm{mFasL} \mathrm{mAb}$, or both, or control rat IgG intraperitoneally ( $250 \mu \mathrm{g}$ each $\mathrm{mAb}$ /injection/mouse) at day $0,5,10$, and 15 after tumor inoculation. Survival of mice was monitored for up to 60 days after tumor inoculation. $P=0.0007$ anti-mTRAIL compared with rat IgG; $P<0.0001$ control, anti-mFasL, and anti-mTRAIL+anti-mFasL compared with rat IgG. The experiments were repeated at least twice. (d) Lysis of B16/hgp100 cells by mTRAIL and mFasL after in vitro treatment with cytokines. B16/hgp100 cells were pre-treated overnight with GM-CSF and TNF- $\alpha$ at $10 \mathrm{ng} \mathrm{ml}^{-1}$ each. Cells were Eu-labeled, and the effector cell lines 2PK-3, L5178Y, mTRAIL/2PK-3, and/or mFasL/L5178Y were added at an effector:target ratio of 20. Data are means with upper $95 \%$ confidence intervals. ${ }^{\ddagger \ddagger} P=0.0002 \mathrm{mFasL} / \mathrm{L} 5178 \mathrm{Y}$ compared with mTRAIL/2PK-3; ${ }^{\Upsilon r} P=0.0008$ mTRAIL+mFasL compared with $\mathrm{mFasL} / \mathrm{L} 5178 \mathrm{Y}$ for GM-CSF+TNF- $\alpha$-treated cells. Similar results were obtained from three independent experiments (a, anti). 
tion of these cytokines in vivo is responsible for antitumor activities. ${ }^{13,33,34,36,37}$

A significant number of immune cells, including $\mathrm{CD}^{+}, \mathrm{CD}^{+}, \mathrm{NK}-1.1$, and CD11c, were found to migrate to the vaccination site of mouse skin in response to RANTES transgene delivery (Figure 6). The recruitment of these immune cells was specific to gene transfection with RANTES, because such infiltration was absolutely not observed in the empty vector-treated mice or normal (untreated) mice. This finding was in line with several earlier reports, showing that chemokines actively attract immune cells. ${ }^{13,30,31}$

As well, we found that the antitumor effect induced by the mRANTES $(0 \mathrm{~h})+\mathrm{hgp} 100(24 \mathrm{~h})$ vaccination involved the TRAIL and FasL signaling pathways to mediate tumor cell death in vivo. However, we could not show this effect in vitro in the absence of TNF- $\alpha$ and GM-CSF. B16/hgp100 melanoma cells were resistant to TRAIL and FasL in vitro but sensitized to TRAIL- and FasL-mediated cell death on exposure to TNF- $\alpha$ and GM-CSF. In vitro

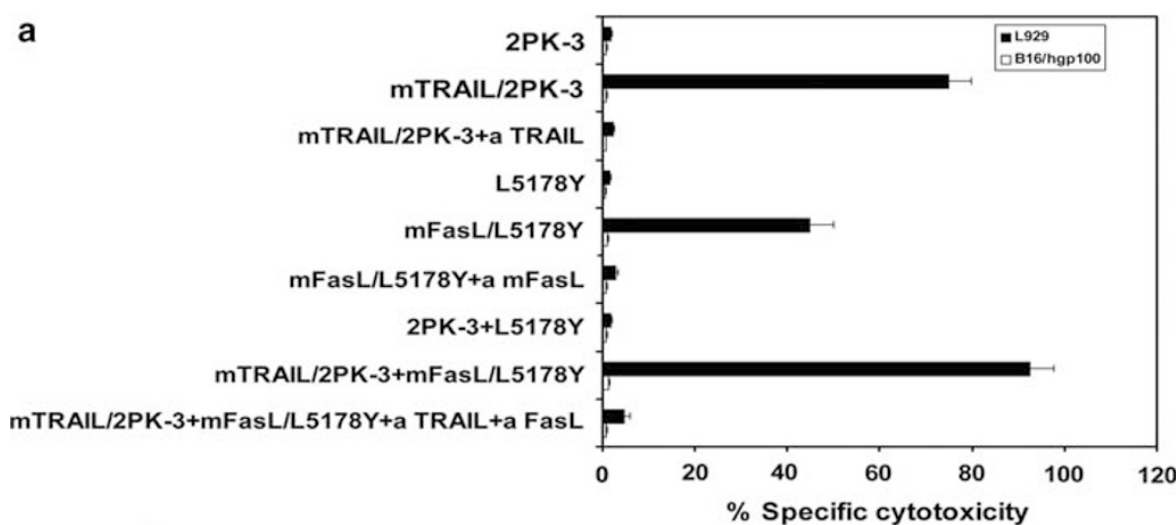

b
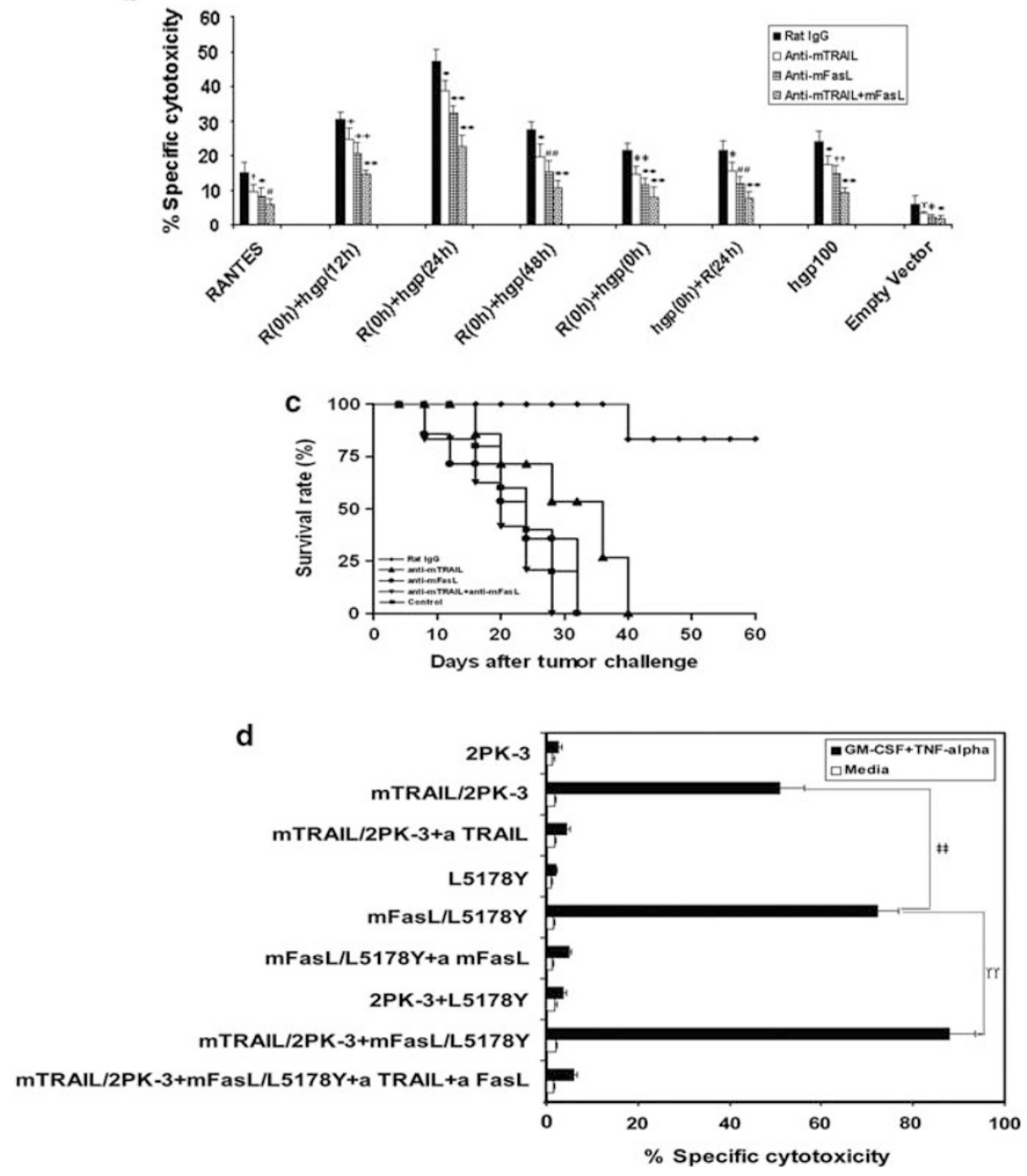
block of effector splenocytes from vaccinated mice using anti-mTRAIL and anti-mFasL mAb significantly reduced CTL activity, which indicates that the CTL responses were mediated at least in part by the TRAIL and FasL signaling pathways. In vivo administration of neutralizing anti-mTRAIL and anti-mFasL mAbs clearly showed the critical involvement of both TRAIL and FasL in the protective immunity induced by mRANTES $(0 \mathrm{~h})+\mathrm{hgp} 100(24 \mathrm{~h})$ vaccination. These results suggest that B16/hgp100 cells were sensitized to TRAIL- and FasL-mediated cell death by effector T-cell-derived cytokines such as TNF- $\alpha$ and GM-CSF in vivo. Our current findings are consistent with those from Renca cells showing increased sensitivity to TRAIL and FasL in response to IFN- $\gamma$ and $\mathrm{TNF}-\alpha,{ }^{38}$ and support our earlier studies of a GM-CSF-enhanced antitumor effect. ${ }^{10}$ Further studies of the GM-CSF and TNF- $\alpha$ effect on B16/hgp100 melanoma would be important for identifying new master molecules regulating the TRAIL and FasL sensitivity of tumor cells.

In conclusion, our current study clearly shows that the correctly timed pre-application of mRANTES gene as an adjuvant in a hgp100 TAA gene vaccination regimen can confer strong antitumor immune responses against B16/ hgp100 melanoma, by effectively inducing and priming immune cell reactions. Such a combination may hence have useful applications for future clinical treatment of patients with melanoma as an alternative to the use of DC-based tumor vaccines, which are complex and costly ex vivo tissue-culture manipulations of patient cells.

\section{Materials and methods}

\section{Animals}

Female C57BL/6JNarl mice (6-8-weeks old) were purchased from the National Laboratory Animal Breeding and Research Center, Taipei, Taiwan. All mice were maintained in a laminar airflow cabinet in a room kept at $24 \pm 2{ }^{\circ} \mathrm{C}$ temperature and $40-70 \%$ humidity with a $12 \mathrm{~h}$ light/dark cycle under specific pathogen-free conditions. All facilities were approved by the Academia Sinica Institutional Animal Care and Utilization Committee, and all animal experiments were conducted under the institutional guidelines established for the Animal Core Facility at Academia Sinica, Taipei.

\section{Cell lines}

The mouse B16F10 (B16) melanoma and hamster fibroblast BHK21 cell lines were obtained from American Type Culture Collection (ATCC; Manassas, VA, USA). Tumor cell cultures were maintained in Dulbecco's modified Eagle's medium with $1.5 \mathrm{~g} \mathrm{l}^{-1}$ sodium bicarbonate, $10 \%$ fetal bovine serum, $100 \mu \mathrm{g} \mathrm{ml}^{-1}$ streptomycin and penicillin, and $2 \mathrm{mM} \mathrm{L-glutamine.} \mathrm{Mouse} \mathrm{B-lympho-}$ ma 2PK-3 and T-lymphoma L5178Y lines were obtained from ATCC and cultured in RPMI 1640 containing $10 \%$ fetal bovine serum, $50 \mu \mathrm{M}$ 2-mercaptoethanol, $100 \mu \mathrm{g} \mathrm{ml}^{-1}$ streptomycin and penicillin, and $2 \mathrm{mM}$ L-glutamine. The $2 \mathrm{PK}-3$ transfectant mTRAIL/2PK-3 and L5178Y transfectant mFasL/L5178Y stably expressing mTRAIL and mFasL, respectively, were generated as described earlier. ${ }^{24}$
Construction of cDNA expression vector, stable transfection, and transgene studies

For B16 cell transfection, a cDNA vector construct pNASS/CMV-hgp100 was generated by inserting the hgp100 cDNA fragment, excised from the pWRG1644 vector, into the pNASS/CMV-neo vector. ${ }^{39}$ B16 cells stably transfected with this hgp100 cDNA vector, designated as B16/hgp100, were obtained as reported earlier. ${ }^{10}$ For vaccine studies, the hgp100 expression plasmid pWRG1644 was constructed by ligating a BamHI/XhoI DNA fragment from pCRII-hgp100 (kindly provided by Dr Nicholas Restifo, National Cancer Institute, Bethesda, MD, USA) into the mammalian expression vector pWRG7077 (PowderJect Vaccines, Madison, WI, USA). pWRG1644 contains a kanamycin resistance gene from Tn903, a human cytomegalovirus immediate-early enhancer/promoter, an intron $A$, the coding sequence for hgp100, and a bovine growth hormone polyadenylation sequence. ${ }^{40}$ The plasmid, pIBSY1, was constructed by cloning a 74-bp DNA fragment coding for the murine IgG $\kappa$-chain leader sequence into the EcoRI-BamHI site of the pIBSY1 vector. The double-stranded 74-bp DNA fragment was obtained by annealing two synthetic oligodeoxynucleotides: $\operatorname{Ig} \kappa \mathrm{Lf}$, 5'-GGCCATGGAGACAGACACACTCCTGCTATGGGT ACTGCTGCTCTGGGTTCCAGGTTCCACTGGTGACG CGGCCG-3' , and Ig $\kappa$ Lr, 5'-AATTCGGCCGCGTCACCA GTGGAACCTGG AACCCAGAGCAGCAGTACCCATA GCAGGAGTGTGTCTGTCTCCAT-3'. All plasmid constructs were fully sequenced, and their authenticity was confirmed. The pORF9-mRANTES mammalian expression vector was purchased from Invivogen (San Diego, CA, USA) and constructed by ligating at BglII/NheI downstream of an elongation factor $(\mathrm{EF}-1 \alpha)$ promoter and 5'-untranslated region of human T-cell leukemia virus hybrid promoter upstream of a simian virus 40 late polyadenylation signal (SV40 polyA), pMB1 Ori, and an ampicillin resistance gene. For DNA immunization, each DNA plasmid was amplified in Escherichia coli strain XL10-Gold (Stratagene, La Jolla, CA, USA) and purified with an Endofree Plasmid Giga kit (Qiagen, Valencia, CA, USA). Purity of DNA preparations was determined by optical density readings at 260 and $280 \mathrm{~nm}$. Transgene expression of hgp100 in vivo was tested by bombardment of plasmid cDNA on mouse abdominal skin, using a Helios (Bio-Rad, Hercules, CA, USA) helium-pulse gene gun with slight modifications as described earlier. ${ }^{40}$ At different time intervals, mice were killed; RNA was extracted (RNA treated with DNase I) from transfected mouse abdominal skin for RT-PCR.

\section{Recombinant MVA construction}

The hgp100 and mRANTES cDNA were amplified from the above-mentioned mammalian plasmid vectors and subcloned into the SalI-PstI site of the pLW44 transfer vector (kindly provided by Dr Bernard Moss, NIH, Bethesda, MD, USA), bringing it under the control of a vaccinia virus-modified $\mathrm{H} 5$ early-late promoter. $^{41}$ The Ig $\kappa$ leader sequence was subcloned into the SmaI-SalI site of pLW44 for secretion of the transgene product. The correct sequences of the hgp100 and mRANTES cDNA inserts were again confirmed by sequencing, and recombinant MVA was made by transfecting transfer plasmids into BHK-21 cells infected 
with 0.05 plaque-forming units (p.f.u.) of MVA per cell. Fluorescent plaques were cloned by eight successive rounds of plaque isolation, then propagated in BHK-21, and titers of recombinant MVA were determined by staining the plaques with antivaccinia virus rabbit antibody. ${ }^{42}$

\section{Preparation of mouse DC and T cells}

Mouse DCs were generated as described earlier, ${ }^{43}$ with slight modifications. To induce DC maturation, some DCs were cultured in the presence of $1 \mu \mathrm{g} \mathrm{ml}^{-1}$ of lipopolysaccharide (Sigma, St Louis, MO, USA) for $24 \mathrm{~h}$ in six-well plates. Twenty-four hours later the mature and immature DCs were collected and tested for cellsurface markers by flow cytometry and finally used for cell migration assay. Spleen cell were labeled with antiCD4 or anti-CD8 magnetic beads and separated on magnetic separation MACS columns (Miltenyi Biotec, Bergisch Gladbach, Germany). ${ }^{44}$ Flow cytometry showed eluted cell populations of $95 \% \mathrm{CD}^{+}$and $97 \% \mathrm{CD}^{+}$(data not shown), and cell samples underwent chemotaxis assay.

\section{Chemotaxis assay}

Briefly, HEK293 cells were transfected with RANTES cDNA using Helios helium-pulse gene gun with slight modifications as we described earlier, ${ }^{39}$ and $48 \mathrm{~h}$ later, medium was collected for chemotaxis assay. DC and T-cell migration activities were analyzed by a transwell system containing polycarbonate membranes with a pore size of 5 or $3 \mu \mathrm{m}$ (Costar, Corning, NY, USA) as described earlier. ${ }^{45,46}$

\section{Gene-based immunization and challenge of mice with tumor cells}

Primary tumor model: C57BL/6 mice were divided into eight experimental groups (eight mice/group), and injected with mRANTES and hgp100 plasmid ( $3 \mu \mathrm{g}$ each/mice) by use of a Bio-Rad Helios gene-gun delivery system as described above. ${ }^{10,40}$ The eight treatments were (i) mRANTES only, (ii) mRANTES $(0 \mathrm{~h})$ followed $12 \mathrm{~h}$ later with hgp100 DNA at the same vaccination site, (iii) mRANTES followed $24 \mathrm{~h}$ later with hgp100, (iv) mRANTES followed $48 \mathrm{~h}$ later with hgp100, (v) mRANTES immediately followed with hgp100, (vi) hgp100 followed $24 \mathrm{~h}$ later with mRANTES, (vii) hgp100 only, and (viii) empty vector DNA only. The above eight vaccination sets were used to treat test mice at the first week for priming, and were followed on weeks 3 and 5 with a booster intraperitoneal injection of the MVA-mRANTES and MVA-hgp100 vectors each (10 7 p.f.u./100 $\mu \mathrm{l} /$ mice). The B16/hgp100 tumor cells for challenge were collected at $80 \%$ confluency, washed in PBS, centrifuged ( $2500 \mathrm{~g}$ for $5 \mathrm{~min}$ ), resuspended in Hanks' balanced salt solution (Life Technologies, Rockville, MD, USA), and injected subcutaneously ( $10^{5}$ cells / $100 \mu \mathrm{l} /$ mouse) into the right flank of mice at 2 weeks post the second boosting with MVA-hgp100 (prophylactic model). Injected mice were examined twice weekly for tumor appearance, and tumor volumes were determined from the length (a) and width (b) of test tumors, as measured in a blinded manner by calipers, by the formula $V=a b^{2} / 2$; survival time of mice was also observed. ${ }^{47}$ Metastasis model: C57BL/6 mice divided into eight experimental sets (eight mice/group) depending on treatment were injected intravenously with B16/ hgp100 tumor cells $\left(10^{5}\right.$ cells $/ 100 \mu \mathrm{l} /$ mouse $)$ on day 0 and then first vaccination at 5 days post tumor cell injection (therapeutic model), and then mice were boosted twice at 5 day intervals. The experiment was terminated on day 21 to observe tumor metastasis into the lung in a blinded manner.

\section{In vivo depletion of immune cell subsets}

C57BL/ 6 mice $(n=7)$ were immunized by mRANTES gene transfection, and $24 \mathrm{~h}$ later vaccination was followed by hgp100 gene delivery at same skin tissue site, then test mice received an intraperitoneal boost on weeks 3 and 5 by transfection with MVA-mRANTES and MVAhgp100 vectors $\left(10^{7}\right.$ p.f.u./ml). One week after the complete gene immunization, right flanks of mice were subcutaneously inoculated with B16/hgp100 tumor cells $\left(10^{5}\right)$. Rat anti-CD4 (GK1.5), anti-CD8 (53-6.7), and antiNK1.1 (PK136) monoclonal antibodies (100 $\mu \mathrm{g} /$ injection/ mice) (all from BioLegend, San Diego, CA, USA) were used to deplete $\mathrm{CD} 4^{+} \mathrm{T}$ cells, $\mathrm{CD} 8^{+} \mathrm{T}$ cells, and NK cells, respectively, on days $-3,0,5,10,15,20,25,30,35$, and 40 . Normal rat IgG (Sigma) was given as a negative control. Target cell depletion was monitored by flow cytometry of peripheral lymphocytes isolated from test mouse blood and stained with fluorescein isothiocyanate-conjugated anti-CD4 ${ }^{+}, \mathrm{CD}^{+}$, and anti-NK-1.1 (data not shown). Survival of mice was observed up to 60 days after tumor challenge.

\section{IFN- $\gamma$ ELISPOT assay}

Human gp100-specific IFN- $\gamma$-secreting spleen cells from test mice were enumerated by ELISPOT assay (R\&D Systems, MN, USA), essentially as described earlier ${ }^{48}$ with slight modifications. Briefly, nitrocellulose-backed plates (96-well, MAHA S45; Millipore, MA, USA) were coated with murine IFN- $\gamma$-specific Ab R4 (BD PharMingen, San Jose, CA, USA) overnight at $4{ }^{\circ} \mathrm{C}$. The wells were washed five times with PBS and blocked using RPMI 1640 supplemented with $10 \%$ fetal bovine serum at $25^{\circ} \mathrm{C}$ for $2 \mathrm{~h}$. Freshly isolated splenocytes $\left(1 \times 10^{5}\right.$ cells $)$ and MMC-treated B16/hgp100 cells were then added into the wells and incubated for $24 \mathrm{~h}$ at $37^{\circ} \mathrm{C}$ in $5 \% \mathrm{CO}_{2}$. The splenocytes without the MMC-treated B16/hgp100 cells were incubated as a negative control. IFN- $\gamma$ spots were counted with use of an immunospot analyzer and confirmed by the computerbased Immunospot software (Cellular Technology, $\mathrm{OH}$, USA). Data in all wells were averaged and normalized by comparing the ratio of antigen-specific spots to negative control spots.

\section{Assay for CTL activity}

To show that tumor-specific CTLs had been generated in the immunized or control mice $(n=3)$, splenocytes were collected 2 weeks after the last immunization and used as effector cells. Target cells (B16/hgp100) were Eulabeled, and nonradioactive DELFIA EuTDA cytotoxicity assay was performed as described. ${ }^{49}$ Briefly, B16/hgp100 tumor cells were collected, washed once, and labeled with DELFIA BATDA reagent (DELFIA, Perkin Elmer, MA, USA) for $30 \mathrm{~min}$ at $37^{\circ} \mathrm{C}$. After a further three washes, $5 \times 10^{3}$ targets (per well) were incubated with effector splenocytes at the indicated ratios of effector to target in 96-well, flat-bottom plates (DELFIA) for $2 \mathrm{~h}$ at $37^{\circ} \mathrm{C}$. The proportion of specific lysis was calculated as 
$100 \times$ (experimental release (counts)-spontaneous release (counts))/[maximum release (counts)-spontaneous release (counts)).

\section{ELISA for cytokine release}

Splenocytes derived from immunized or control mice $(n=3) 2$ weeks after the second boosting were collected and washed three times with PBS. Then, splenocytes $\left(2 \times 10^{6}\right.$ cells $\left./ \mathrm{ml}\right)$ were stimulated with MMC-treated B16/hgp100 cells at a 10:1 ratio. Culture supernatants were collected after $48 \mathrm{~h}$ and assayed for IFN- $\gamma$, IL-10, TNF- $\alpha$, and GM-CSF. The level of cytokines was determined by use of ELISA kits (R\&D Systems, MA, USA).

\section{Immunohistochemical analysis}

Rat antimouse CD4 and rat antimouse CD8 were purchased from BD Pharmingen. Antimouse NK-1.1 and antimouse CD11c were purchased from BioLegend. Before antibody staining, cryostat sections (5-7 $\mu \mathrm{m})$ were placed on glass slides, air-dried, and fixed in $4 \%$ paraformaldehyde/PBS for $10 \mathrm{~min}$. Slides were sequentially incubated with diluted primary $\mathrm{Ab}$ overnight at $4{ }^{\circ} \mathrm{C}$ and $\mathrm{Ab}$ were detected using IHC Select immunoperoxidase secondary detection system (Chemicon, Temecula, CA, USA).

In vivo treatment with anti-mTRAIL and anti-mFasL Neutralizing anti-mTRAIL (N2B2) and anti-mFasL (MFL1) were prepared as described earlier. ${ }^{24}$ For in vivo blocking of mTRAIL and mFasL, some immunized mice received anti-mTRAIL $\mathrm{mAb}$ or anti-mFasL $\mathrm{mAb}$, or both, or control (rat IgG) intraperitoneally at $250 \mu \mathrm{g}$ each $\mathrm{mAb}$ /injection/mouse on days $0,5,10$, and 15 after tumor inoculation.

\section{Sensitivity of B16/hgp100 cells to TRAIL and FasL} A standard nonradioactive DELFIA EuTDA cytotoxicity assay was performed as described above. Briefly, B16/ hgp100 target cells were labeled with DELFIA BATDA reagent for $30 \mathrm{~min}$ at $37^{\circ} \mathrm{C}$. In some experiments, B16/ hgp100 cells were incubated overnight with or without GM-CSF and/or TNF- $\alpha$ (10 $\mathrm{ng} \mathrm{ml}^{-1}$ each) before Eulabeling. After a washing, $5 \times 10^{3}$ target cells (per well) were incubated with mTRAIL/2PK-3, mFasL/L5178Y, $2 \mathrm{PK}-3$, or L5178Y cells (functioning as effector cells) in 96-well, flat-bottom plates at a ratio of 20. TRAIL and FasL-sensitive murine fibrosarcoma L929 cells were used as a positive control. In some experiments, effector cells from the immunized (mRANTES $(0 \mathrm{~h})+\mathrm{hgp} 100(24 \mathrm{~h})$ regimen) or control mice were used to determine the involvement of TRAIL and FasL in cytotoxic activity in B16/hgp100 cells. Anti-mTRAIL and/or anti-mFasL $\mathrm{mAbs}$ were added to a final concentration of $10 \mu \mathrm{g} \mathrm{ml}^{-1}$ at the start of the cytotoxicity assay.

\section{Statistical analysis}

Data are presented as means with $95 \%$ confidence intervals (CI) of at least three experiments. Statistical analyses were carried out with GraphPad Prism 4.0 (San Diego, CA, USA). Groups were compared by Student's $t$-test. Differences in survival time were evaluated by a log-rank test of the Kaplan-Meier survival curves. All statistical tests were two-sided.
$P$-values less than 0.05 were considered statistically significant.

\section{Acknowledgements}

This work was supported by a Grant (94-2320-B-001-044)

from the National Science Council, Taiwan.

\section{References}

1 Lanzavecchia A. Identifying strategies for immune intervention. Science 1993; 60: 937-944.

2 Kawakami Y, Eliyahu S, Delgado CH, Robbins PF, Sakaguchi K, Appell $\mathrm{E}$ et al. Identification of a human melanoma antigen recognized by tumor-infiltrating lymphocytes associated with in vivo tumor rejection. Proc Natl Acad Sci USA 1994; 91: 6458-6462.

3 Bloom MB, Perry-Lalley D, Robbins PF, Li Y, El-Gamil M, Rosenberg SA et al. Identification of a human tyrosinase-related protein 2 as a tumor rejection antigen for the B16 melanoma. J Exp Med 1997; 185: 453-459.

4 Coulie PG, Brichard V, Pel AV, Wolfel T, Schneider J, Traversari C et al. A new gene coding for a differentiation antigen recognized by autologous cytolytic T lymphocytes on HLA-A2 melanomas. J Exp Med 1994; 180: 35-42.

5 Perricone MA, Claussen KA, Smith KA, Kaplan JM, Piraino S, Shankara $S$ et al. Immuno gene therapy for murine melanoma using recombinant adenoviral vectors expressing melanomaassociated antigens. Mol Ther 2000; 1: 275-284.

6 Zhai Y, Yang JC, Spiess P, Nishimura MI, Overwijk WW, Roberts $\mathrm{B}$ et al. Cloning and characterization of the genes encoding the murine homologues of the human melanoma antigens MART1 and gp100. J Immunother 1997; 20: 15-25.

7 Wan Y, Emtage P, Zhu Q, Foley R, Pilon A, Roberts B et al. Enhanced immune response to the melanoma antigen gp100 using recombinant adenovirus-transduced dendritic cells. Cell Immunol 1999; 198: 131-138.

8 Ferrone CR, Perales MA, Goldberg SM, Somberg CJ, Cymerman $\mathrm{DH}$, Gregor PD et al. Adjuvanticity of plasmid DNA encoding cytokines fused to immunoglobulin Fc domains. Clin Cancer Res 2006; 12: 5511-5519.

9 Zhao L, Gu J, Dong A, Zhang Y, Zhong L, He L et al. Potent antitumor activity of oncolytic adenovirus expressing mda-7/ IL-24 for colorectal cancer. Hum Gene Ther 2005; 16: 845-858.

10 Rakhmilevich AL, Imboden M, Hao Z, Macklin MD, Roberts T, Wright KM et al. Effective particle-mediated vaccination against mouse melanoma by coadministration of plasmid DNA encoding gp100 and granulocyte-macrophage colony-stimulating factor. Clin Cancer Res 2001; 7: 952-961.

11 Ward SG, Westwick J. Chemokines: understanding their role in T-lymphocyte biology. Biochem J 1998; 333: 457-470.

12 Rossi D, Zlotnik A. The biology of chemokines and their receptors. Annu Rev Immunol 2000; 18: 217-242.

13 Yamano T, Kaneda Y, Huang S, Hiramatsu SH, Hoon DSB. Enhancement of immunity by a DNA melanoma vaccine against TRP2 with CCL21 as an adjuvant. Mol Ther 2006; 13: 194-202.

14 Schall TJ. Biology of the RANTES/SIS cytokine family. Cytokine 1991; 3: 165-183.

15 Mule JJ, Custer M, Averbook B, Yang JC, Weber JS, Goeddel DV et al. RANTES secretion by gene-modified tumor cells results in loss of tumorigenicity in vivo: Role of immune cell subpopulations. Hum Gene Ther 1996; 7: 1545-1553.

16 Nakazaki Y, Hase H, Inoue H, Beppu Y, Xin MK, Sakaguchi G et al. Serial analysis of gene expression in progressing and regressing mouse tumors implicates the involvement of RANTES and TARC in antitumor immune responses. Mol Ther 2006; 14: 599-606. 
17 Wagner L, Yang OO, Garcia-Zepeda EA, Ge Y, Kalams SA, Walker BD et al. Beta-Chemokines are released from HIV-1specific cytolytic T-cell granules complexed to proteoglycans. Nature 1998; 391: 908-911.

18 Hadida F, Vieillard V, Autran B, Clark-Lewis I, Baggiolini M, Debré P. HIV-specific T cell cytotoxicity mediated by RANTES via the chemokine receptor CCR3. J Exp Med 1998; 188: 609-614.

19 Schneider J, Gilbert SC, Blanchard TJ, Hanke T, Robson KJ, Hannan $\mathrm{CM}$ et al. Enhanced immunogenicity for $\mathrm{CD}^{+} \mathrm{T}$ cell induction and complete protective efficacy of malaria DNA vaccination by boosting with modified vaccinia virus Ankara. Nat Med 1998; 5: 397-402.

20 Mcconkey SJ, Reece WH, Moorthy VS, Webster D, Dunachie S, Butcher $G$ et al. Enhanced T-cell immunogenicity of plasmid DNA vaccines boosted by recombinant modified vaccinia virus Ankara in humans. Nat Med 2003; 9: 729-735.

21 Henkart PA, Sitkovsky MV. Cytotoxic lymphocytes: two ways to kill target cells. Curr Biol 1994; 4: 923-925.

22 Takeda K, Hayakawa Y, Smyth MJ, Kayagaki N, Yamaguchi N, Kakuta $\mathrm{S}$ et al. Involvement of tumor necrosis factor-related apoptosis-inducing ligand in surveillance of tumor metastasis by liver natural killer cells. Nat Med 2001; 7: 94-100.

23 Seki N, Hayakawa Y, Brooks AD, Wine J, Wiltrout RH, Yagita H et al. Tumor necrosis factor-related apoptosis-inducing ligandmediated apoptosis is an important endogenous mechanism for resistance to liver metastases in murine renal cancer. Cancer Res 2003; 63: 207-213.

24 Kayagaki N, Yamaguchi N, Nakayama M, Takeda K, Akiba H, Tsutsui $\mathrm{H}$ et al. Expression and function of TNF-related apoptosis-inducing ligand on murine activated NK cells. I Immunol 1999; 163: 1906-1913.

25 Sallusto F, Lanzavecchia A. Understanding dendritic cell and T-lymphocyte traffic through the analysis of chemokine receptor expression. Immunol Rev 2000; 177: 134-140.

26 Mantovani A, Sica A, Sozzani S, Allavena P, Vecchi A, Locati M. The chemokine system in diverse forms of macrophage activation and polarization. Trends Immunol 2004; 25: 677-686.

27 Laning J, Kawasaki H, Tanaka E, Luo Y, Dorf ME. Inhibition of in vivo tumor growth by the $\beta$ chemokine, TCA3. J Immunol 1994; 153: $4625-4635$.

28 Nagira M, Imai T, Yoshida R, Takagi S, Iwasaki M, Baba M et al. A lymphocyte-specific CC chemokine, secondary lymphoid tissue chemokine (SLC), is a highly efficient chemoattractant for B cells and activated T cells. Eur J Immunol 1998; 28: 1516-1523.

29 Braun SE, Chen K, Foster RG, Kim CH, Hromas R, Kaplan MH et al. The CC chemokine CK $\beta-11 /$ MIP-3 $\beta /$ ELC/Exodus 3 mediates tumor rejection of murine breast cancer cells through NK cells. J Immunol 2000; 164: 4025-4031.

30 Sharma S, Stolina M, Luo J, Strieter RM, Burdick M, Zhu LX et al. Secondary lymphoid tissue chemokine mediates T-cell-dependent antitumor responses in vivo. J Immunol 2000; 164: 4558-4563.

31 Vicari AP, Ait-Yahia S, Chemin K, Mueller A, Zlotnik A, Caux C. Antitumor effects of the mouse chemokine 6Ckine/SLC through angiostatic and immunological mechanisms. J Immunol 2000; 165: 1992-2000.

$32 \mathrm{Kim} \mathrm{CH}$, Pelus LM, Appelbaum E, Johanson K, Anzai N, Broxmeyer HE. CCR7 ligands, SLC/6Ckine/Exodus2/TCA4 and CK $\beta-11 / \mathrm{MIP}-3 \beta / \mathrm{ELC}$, are chemoattractants for CD56+CD16 NK cells and late stage lymphoid progenitors. Cell Immunol 1999; 193: 226-235.

33 Yang SC, Batra RK, Hillinger S, Reckamp KL, Strieter RM, Dubinett SM et al. Intrapulmonary administration of CCL21 gene-modified dendritic cells reduced tumor burden in spontaneous murine bronchoalveolar cell carcinoma. Cancer Res 2006; 66: 3205-3213.
34 Lian H, Jin N, Li X, Mi Z, Zhang J, Sun L et al. Induction of an effective anti-tumor immune response and tumor regression by combined administration of IL-18 and apoptin. Cancer Immunol Immunother 2007; 56: 181-192.

35 Zhang Y, Yoneyama H, Wang Y, Ishikawa S, Hashimoto SI, Gao LI et al. Mobilization of dendritic cell precursors into the circulation by administration of MIP- $1 \alpha$ in mice. J Natl Cancer Inst 2004; 96: 201-209.

36 Paczesny S, Banchereau J, Wittkowski KM, Saracino G, Fay J, Palucka AK. Expansion of melanoma-specific cytolytic CD8 ${ }^{+} \mathrm{T}$ cell precursors in patients with metastatic melanoma vaccinated with CD34 ${ }^{+}$progenitor-derived dendritic cells. J Exp Med 2004; 199: 1503-1511.

37 Luo Y, Zhou H, Mizutani M, Mizutani N, Liu C, Xiang R et al. A DNA vaccine targeting Fos-related antigen 1 enhanced by IL-18 induces long-lived T-cell memory against tumor recurrence. Cancer Res 2005; 65: 3419-3427.

38 Sayers TJ, Brooks AD, Seki N, Smyth MJ, Yagita H, Blazar BR et al. $\mathrm{T}$ cell lysis of murine renal cancer: Multiple signaling pathways for cell death via Fas. J Leukoc Biol 2000; 68: 81-86.

39 Albertini MR, Emler CA, Schell K, Tans KJ, King DM, Sheehy MJ. Dual expression of human leukocyte antigen molecules and the B7-1 costimulatory molecule (CD80) on human melanoma cells after particle-mediated gene transfer. Cancer Gene Ther 1996; 3: 192-201.

40 Rakhmilevich AL, Turner J, Ford MJ, Mccabe D, Sun WH, Sondel $\mathrm{PM}$ et al. Gene gun-mediated skin transfection with Interleukin 12 gene results in regression of established primary and metastatic murine tumors. Proc Natl Acad Sci USA 1996; 93: 6291-6296.

41 Wyatt LS, Shors ST, Murphy BR, Moss B. Development of a replication-deficient recombinant vaccinia virus vaccine effective against parainfluenza virus 3 infection in an animal model. Vaccine 1996; 14: 1451-1458.

42 Earl PL, Moss B, Wyatt LS, Carroll MW. Generation of recombinant vaccinia viruses. In: Ausubel FM, Brent R, Kingston RE, Moore DD, Seidmen ZG, Smith ZA, Skuhl LX (eds). Current Protocols in Molecular Biology. John Wiley and Sons: NewYork, 1998. pp 16.17.1-16.19.11.

43 Labeur MS, Roters B, Pers B, Mehling A, Luger TA, Schwarz T et al. Generation of tumor immunity by bone marrow-derived dendritic cells correlates with dendritic cell maturation stage. J Immunol 1999; 162: 168-175.

44 Tomura M, Maruo S, Mu J, Zhou XY, Ahn HJ, Hamaoka Tet al. Differential capacities of $\mathrm{CD}^{+}, \mathrm{CD}^{+}$, and $\mathrm{CD} 4{ }^{-} \mathrm{CD} 8^{-} \mathrm{T}$-cell subsets to express IL-18 receptor and produce IFN- $\gamma$ in response to IL-18. J Immunol 1999; 60: 3759-3765.

45 Rubbert A, Combatiere C, Ostrowski M, Arthos J, Dybul M, Machado E et al. Dendritic cells express multiple chemokine receptors used as coreceptors for HIV entry. J Immunol 1998; 160: 3933-3941.

46 Vroon A, Heijnen CJ, Lombardi MS, Cobelens PM, Mayor J, Caron MG et al. Reduced GRK2 level in T cells potentiates chemotaxis and signaling in response to CCL4. J Leukoc Biol 2004; 75: 901-909.

47 Conway TF, Sabel MS, Sugano M, Frelinger JG, Egilmez NK, Chen $\mathrm{F}$ et al. Growth of human tumor xenografts in SCID mice quantified using an immunoassay for tumor marker protein in serum. J Immunol Methods 2000; 233: 57-65.

48 Herd KA, Harvey T, Khromykh AA, Tindle RW. Recombinant Kunjin virus replicon vaccines induce protective T-cell immunity against human papillomavirus 16 E7-expressing tumor. Virology 2004; 319: 237-248.

49 Acres B, Gantzer M, Remy C, Futin N, Accart N, Chaloin O et al. Fusokine interleukin-2/interleukin-18, a novel potent innate and adaptive immune stimulator with decreased toxicity. Cancer Res 2005; 65: 9536-9546. 